\title{
Temporal uncertainty degrades perceptual processing
}

\author{
Bettina Rolke and Peter Hofmann \\ University of Tübingen, Tübingen, Germany
}

\begin{abstract}
When participants are required to react to a stimulus, reaction times (RTs) are usually reduced when temporal uncertainty about stimulus occurrence is minimized. Contrary to the common assumption attributing this RT benefit solely to the speeding of motor processes, recent evidence suggests that temporal uncertainty might rather influence premotoric processing levels. We employed a backward-masking procedure to further confine the locus of the temporal uncertainty effect. Participants performed a discrimination task and indicated whether a spatial gap within a square was on the right or the left side. In addition to the shorter RTs, visual discrimination accuracy was improved when temporal uncertainty was low. This result demonstrates that temporal uncertainty influences stimulus processing at a perceptual level.
\end{abstract}

When participants can anticipate the temporal occurrence of a stimulus, the reaction time (RT) to this stimulus is especially short. Since the study of Woodrow (1914), this RT benefit has been repeatedly demonstrated (Klemmer, 1956; Niemi \& Näätänen, 1981) and shown to be robust. For example, the benefit is not only observed for visual but for auditory stimuli, and also in crossmodal stimulus situations (see, e.g., Müller-Gethmann, Ulrich, \& Rinkenauer, 2003). Usually, the effect has been studied by the presentation of a warning signal that announces the occurrence of the imperative stimulus. Even though the warning signal contains no information about the required response, the RT benefit is also observed for choice RTs (see, e.g., Simon \& Slaviero, 1975). According to Niemi and Näätänen, the warning signal reduces the uncertainty about when the imperative stimulus will occur, which in turn promotes temporal preparation of the response.

In order to better understand the mechanisms that underlie this temporal preparation effect, several studies have aimed to localize the effect within the processing stream from the perceptual input to the corresponding response (for reviews, see Hackley \& Valle-Inclán, 2003; Müller-Gethmann et al., 2003). The locus of the effect, however, is still unclear. Some theorists assume that temporal preparation influences late motor processes (e.g., Hohle, 1965; Sanders, 1998; Teichner, 1954). This assumption is supported by RT studies (e.g., Sanders, 1980, 1998; Spijkers, 1990) that have employed the additivefactor method (AFM; Sternberg, 2001), as well as by several other studies that have assessed the effects of temporal uncertainty on the correlates of motor processes. For example, studies have included such measures as response force (Mattes \& Ulrich, 1997), reflex amplitude (Brunia \& van Boxtel, 2000), transcranially evoked motoric poten- tials (Hasbroucq, Kaneko, Akamatsu, \& Possamaï, 1999), and the contingent negative variation (Loveless, 1973). All of these studies concluded that the manipulation of temporal uncertainty affects motor processes.

Other theorists, however, have challenged the notion that temporal preparation operates exclusively or primarily at a late motoric level (Hackley \& Valle-Inclán, 1998, 1999; Müller-Gethmann et al., 2003; Smulders, 1993). This challenge is based on chronophysiological studies employing lateralized readiness potentials (LRPs) that bisect RTs into early and late phases. Contrary to the prevailing view, the results of these studies have shown that a reduction of temporal uncertainty shortens the early but not the late portion of an RT. Hence, these studies support the conclusion that temporal preparation facilitates the speed of rather early processes.

Additional evidence for a premotoric ${ }^{1}$ locus of the temporal uncertainty effect has emerged from a recent study by Bausenhart, Rolke, Hackley, and Ulrich (2006). Those authors used the effect propagation property (Miller \& Reynolds, 2003) of the psychological refractory period paradigm (PRP; Pashler \& Johnston, 1998) to obtain further, independent evidence regarding the locus of the temporal preparation effect. Their paradigm required that participants perform two successive yet temporally overlapping RT tasks, and temporal uncertainty of the first task was manipulated. Consistent with the prediction of a premotoric locus of temporal uncertainty, the effect of temporal uncertainty propagated completely from the first task to the second. On the basis of this outcome, the authors concluded that the speed of early processing levels is affected by temporal uncertainty.

Taken together, the studies cited above provide a somewhat mixed picture concerning the locus of the temporal

B. Rolke, bettina.rolke@uni-tuebingen.de 
uncertainty effect. AFM studies and studies in which correlates of motor processes were measured concluded that temporal uncertainty operates at late motoric processing levels. More recent chronophysiological studies and the PRP study, however, support the notion that earlier, premotoric processing levels constitute an additional locus of the temporal uncertainty effect. Even though the latter studies provided strong evidence for a premotoric locus of the temporal uncertainty effect, they have not been able to precisely localize this effect within premotoric stimulus processing. Specifically, within the psychophysiological studies, the LRP onset provides a temporal marker for completion of response selection and allows partition of RTs only into two segments, one including processing levels later than response selection (i.e., response execution), the other including several earlier premotoric processes (i.e., the perceptual, decision, and response selection stages). Therefore, this account cannot distinguish between a perceptual and a more central locus of the temporal uncertainty effect. A similar limitation applies to the PRP study (Bausenhart et al., 2006): Since the effect propagation logic of the PRP is based on the assumption that the bottleneck in processing emerges from a response selection bottleneck (see, e.g., Pashler, 1994; Sommer, Leuthold, \& Schubert, 2001), even this study was not able to localize the influence of temporal uncertainty on different premotoric processes. Thus, the issue of whether the temporal uncertainty effect is restricted to central processing stages or influences stimulus processing at a perceptual level remains unresolved.

The aim of the present study was to assess whether temporal uncertainty affects perceptual stimulus processing. In order to manipulate temporal uncertainty for the occurrence of the target stimulus, we employed a blocked foreperiod paradigm, in which foreperiod length (i.e., the temporal interval between the warning signal and the imperative response signal) was constant within a block of trials but changed across blocks. The standard result of this approach has been that RTs increase progressively as the foreperiod length is increased (Niemi \& Näätänen, 1981). According to Klemmer (1956), the prolonged RTs for lengthened foreperiods reflect increasing difficulty in estimating the time at which the response signal will occur. Hence, lengthened foreperiods produce a higher amount of temporal uncertainty.
The task of the participants in our study was to judge whether a small spatial gap within a target stimulus (a square) was on the right or the left side. To investigate perceptual stimulus processing, we employed a backward masking procedure (Breitmeyer, 1984; Turvey, 1973) and presented a random visual noise pattern shortly after the target stimulus. This kind of masking is known to selectively influence early perceptual stimulus processing (see, e.g., Bachmann \& Allik, 1976; Smith \& Wolfgang, 2004; Turvey, 1973). The square was presented for three different time intervals $(32,48$, or $64 \mathrm{msec})$ before being masked. This variation in target duration was introduced in order to provide an adequate difficulty range for the perceptual task and to avoid saturation effects. If temporal uncertainty influences processing levels later than perceptual processing, we would expect to find no influence of foreperiod length on gap discrimination performance. If, however, temporal uncertainty affects perceptual stimulus processing, we would expect better discrimination performance for the short than for the long foreperiod.

\section{METHOD}

\section{Participants}

Twenty participants ( 17 women and 3 men) took part in this study (mean age, 25.1 years).

\section{Stimuli and Apparatus}

Stimulus presentation is illustrated in Figure 1. All stimuli were presented in gray $\left(27 \mathrm{~cd} / \mathrm{m}^{2}\right)$ on the dark blue background $\left(0.8 \mathrm{~cd} / \mathrm{m}^{2}\right)$ of a computer screen and were viewed from a distance of approximately $50 \mathrm{~cm}$. The stimuli consisted of a fixation $\operatorname{dot}\left(0.12^{\circ} \times 0.12^{\circ}\right.$ of visual angle), a warning signal (an asterisk with a diameter of $\left.0.57^{\circ}\right)$, a random noise mask $\left(1.26^{\circ} \times 1.26^{\circ}\right)$, and a square $\left(1.15^{\circ} \times\right.$ $\left.1.15^{\circ}\right)$ that had a small gap $\left(0.12^{\circ}\right)$ on either the left or the right side. To reduce spatial uncertainty, all stimuli were presented within a small quadratic frame $\left(2.52^{\circ} \times 2.52^{\circ}\right)$ at the center of the monitor. There were separate response panels for the index fingers of the two hands.

\section{Procedure and Design}

Each trial started with the presentation of the fixation dot, which was displayed for an interval of $(0.5+X) \mathrm{sec}$, in which $X$ was a random variable that followed an exponential distribution with a mean of $1 \mathrm{sec}$. This random interval was introduced in order to emphasize the importance of the warning signal as a temporal reference for preparation (Müller-Gethmann et al., 2003). At the end of the inter$\mathrm{val}$, the fixation dot was replaced by the warning signal (asterisk) for $200 \mathrm{msec}$. At the warning signal offset, the fixation dot reappeared,

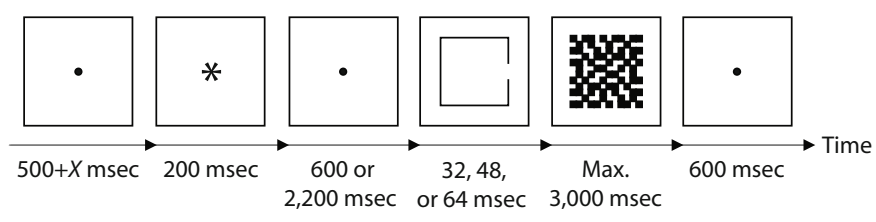

Figure 1. Time course of a single trial. In order to reduce spatial uncertainty, all stimuli were presented within a small quadratic frame at the center of the monitor. Following the variable presentation time of the fixation dot, the warning signal (asterisk) provided a cue for temporal preparation. After a blocked foreperiod length of 800 or $2,400 \mathrm{msec}$, the square appeared for 32,48 , or $64 \mathrm{msec}$. The square was then displaced by a noise mask consisting of a random dot pattern. Participants had to judge whether the gap in the square was on the left or the right side. 
to be replaced after 600 or $2,200 \mathrm{msec}$ by the square. Thus, the foreperiod length between the onset of the warning signal and the onset of the square was either 800 or $2,400 \mathrm{msec}$ for any given block of trials. The square was then replaced by the mask, yielding target durations of 32, 48, or $64 \mathrm{msec}$. The mask was terminated with the response or after 3,000 $\mathrm{msec}$, and the fixation dot then reappeared for another $600 \mathrm{msec}$. Participants indicated by a keypress whether the gap occurred in the left or the right side of the square. Participants were asked to press the left key with the left index finger if the gap appeared in the left side, or the right key with the right index finger if the gap appeared in the right side. They were asked to respond correctly and quickly, although accuracy was emphasized.

A single session lasted about $1 \mathrm{~h}$ and consisted of 24 blocks. Foreperiod length was kept constant over 12 consecutive blocks of 24 trials each, whereas target duration was varied within a block of trials. The order of the two foreperiod conditions was balanced across all participants. The first 2 blocks of each foreperiod condition were considered practice and discarded from data analysis. After each block, participants received feedback concerning their percentages of correct responses.

The experiment factorially combined foreperiod length ( $800 \mathrm{vs}$. $2,400 \mathrm{msec}$ ), target duration (32, 48, or $64 \mathrm{msec})$, and gap position (left vs. right).

\section{RESULTS}

RTs shorter than $200 \mathrm{msec}$ or greater than 1,000 msec were considered outliers, and the corresponding trials were discarded $(2.1 \%){ }^{2}$ Separate repeated measures ANOVAs with the factors foreperiod length and target duration were conducted on mean RTs of correct responses and on discrimination performance $\left(d^{\prime}\right) .{ }^{3}$ The $p$ values were adjusted, whenever appropriate, for violations of the sphericity assumption using the Greenhouse-Geisser correction.

The results are summarized in Figure 2, which depicts mean RTs and $d^{\prime}$ s as a function of foreperiod length and target duration. An ANOVA on RTs revealed that the manipulation of temporal preparation was successful, because mean RTs increased with foreperiod length as a result of increasing temporal uncertainty $[F(1,19)=41.9$, $p<.001]$. As one would expect, mean RTs decreased with increasing presentation time $[F(2,38)=36.1, p<.001]$. The two factors also produced a significant interaction $[F(2,38)=4.3, p<.05]$ indicating a saturation of mean $\mathrm{RT}$ in the short foreperiod condition.

As expected, and consistent with previous studies (e.g., Bachmann \& Allik, 1976), $d^{\prime}$ increased with increasing target duration $[F(2,38)=49.1, p<.001]$. Most important, however, foreperiod length clearly influenced $d^{\prime}$ $[F(1,19)=15.2, p<.01]$. As temporal uncertainty increased with foreperiod length, $d^{\prime}$ decreased. This result strongly suggests an influence of temporal preparation on perceptual stimulus processing. This foreperiod effect was not influenced by target duration $(p>.18)$, and there were no significant differences in response bias $\left(c ;{ }^{4}\right.$ all $p \mathrm{~s}>.23)$.

\section{DISCUSSION}

This study was conducted to localize the effect of temporal preparation in the processing chain from stimulus input to response. Specifically, we addressed the ques- tion of whether temporal preparation improves perceptual stimulus processing. A backward-masking manipulation, which is selectively sensitive to perceptual processes, was used to address this question. The results were clear cut: First, and as expected, a sizeable foreperiod effect on RTs was observed, indicating a successful implementation of temporal uncertainty. Second, and of theoretical importance, temporal uncertainty influenced discrimination performance with the target stimulus, in that performance was enhanced when temporal uncertainty was low. This pattern of results revealed that temporal preparation exerts its effect prior to response selection - that is, at a perceptual level of signal processing.

The benefit of temporal preparation for perceptual processing might be comprehensible in terms of the probable mechanism that contributes to the backward-masking effect. According to the interruption theory of masking (Kahneman, 1968; Sperling, 1963), the delayed arrival of the mask disrupts the processing of the target and erases its visual memory trace. As a consequence, target processing has to occur during the limited target duration, before the processing is erased by the mask. Suppose that, in addition, response decisions are based on an internal criterion value. According to such a criterion model (for a review, see Luce, 1986), physical stimulation is transduced into some internal activation that is accumulated over time. As soon as the accumulated information reaches the criterion

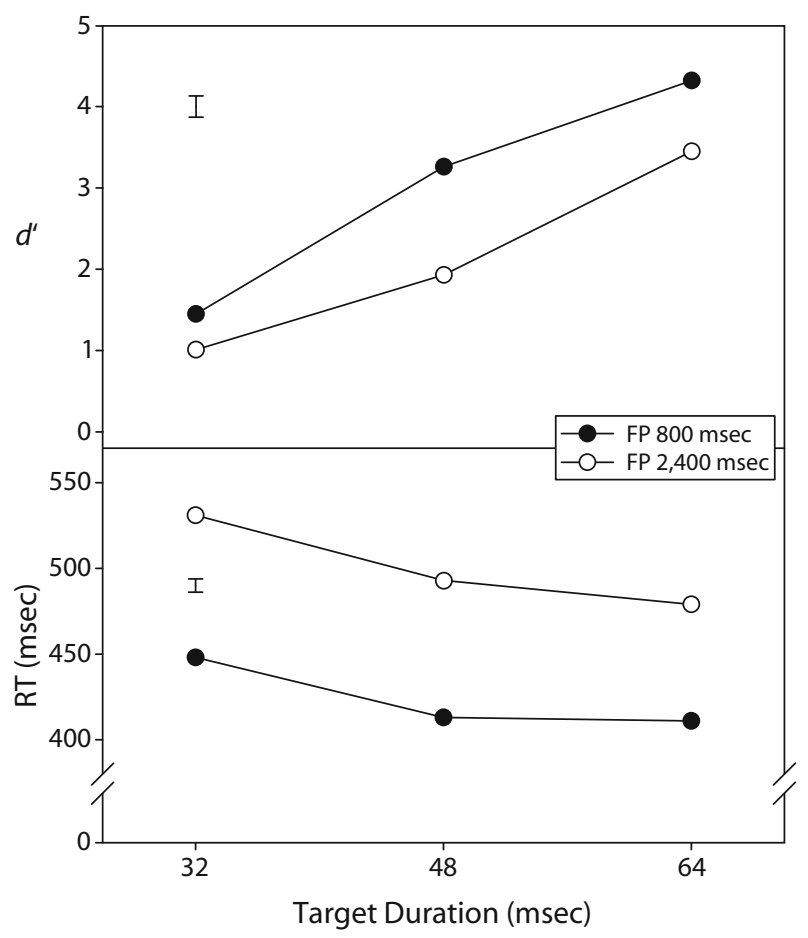

Figure 2. Discrimination performance $\left(d^{\prime}\right)$ and mean reaction times (RTs) of correct responses as a function of foreperiod length (FP; $800 \mathrm{vs.} 2,400 \mathrm{msec}$ ) and target duration (32, 48, and $64 \mathrm{msec})$. The standard error was computed from the pooled error terms of the corresponding ANOVA, according to a suggestion made by Loftus (2002). 
value, a decision is made and a motor response is initiated (Grice, 1968; Luce, 1986).

Assume now that reduced temporal uncertainty increases the preparation for target onset. As a consequence, in the short foreperiod condition, perceptual processing of the stimulus may begin earlier, and accumulated evidence can increase to a higher level before the target stimulus is masked. This proposed model predicts better gap discrimination performance when temporal certainty is relatively high, because the response decision is then based on a greater amount of accumulated evidence. Moreover, this model also predicts an early effect of temporal uncertainty on RTs. Because of the assumed earlier beginning of the accumulation process when temporal certainty is high, the criterion value will be reached faster and so will decrease RTs in the short foreperiod condition.

According to this proposed mechanism, our study suggests that reduced temporal uncertainty allows better anticipation of the onset of the target stimulus, which in turn might accelerate the accumulation of perceptual evidence for a response decision. This conclusion agrees with the results from recent chronophysiological studies in which temporal uncertainty was manipulated using either short foreperiods (Hackley \& Valle-Inclán, 1998, 1999); short, medium, and long foreperiods (Müller-Gethmann et al., 2003); or variable versus fixed intertrial intervals (Smulders, 1993). The conclusion is also in line with the PRP study discussed in the introduction (Bausenhart et al., 2006), which used the effect propagation logic (Miller \& Reynolds, 2003) of the PRP and localized the temporal uncertainty effect prior to or at the response selection bottleneck. Moreover, our result extends the present knowledge, and strongly suggests a perceptual locus of the temporal uncertainty effect.

Our conclusion that temporal uncertainty elicits a perceptual effect, however, does not mean that such uncertainty exclusively influences perceptual processing stages. For example, both the chronophysiological studies mentioned above and the PRP study leave open the possibility that response selection constitutes an additional locus of the temporal uncertainty effect. Furthermore, the data from AFM studies (e.g., Sanders, 1980, 1998) show that instructed muscle tension modulates the foreperiod effect on RTs, and several other studies have reported an effect of temporal uncertainty on correlates of motor processes (e.g., Brunia \& van Boxtel, 2000; Mattes \& Ulrich, 1997). Therefore, although the present results argue for a perceptual locus of temporal uncertainty, they do not exclude the possibility that temporal uncertainty might also influence response preparation and motor execution processes.

The present result is consistent with recent findings by Correa, Lupiáñez, and Tudela (2005). These authors employed a different experimental manipulation to induce temporal preparation by orienting temporal attention with a temporal cue (see, e.g., Coull \& Nobre, 1998). In each trial, a visual cue indicated whether a visual target was likely to appear early or late among a rapidly presented stream of distractor stimuli. Detection performance for the targets presented at the expected time interval was higher than detection performance for targets that appeared at an unexpected time interval. This result indicates that attentional preparation modulates processing at a perceptual level. A similar conclusion was recently reached by Martens and Johnson (2005). Those authors investigated the influence of temporal preparation on the attentional blink phenomenon - that is, a failure to identify a second target if it appears shortly after the presentation of a first target (Raymond, Shapiro, \& Arnell, 1992). Cuing the temporal onset between the targets reduced the magnitude of the attentional blink, indicating that temporal cues might be useful in distinguishing relevant from irrelevant information and might help with selecting targets within a temporal stream of distractors. Therefore, both studies agree with the conclusion that temporal preparation improves perceptual stimulus processing.

The present finding of a perceptual locus of temporal uncertainty reveals an analogy between the preparation effects within the temporal and spatial domains of stimulus processing. Specifically, just as reduced temporal uncertainty has resulted in an RT benefit in the temporal domain, reduced spatial uncertainty due to spatial cues produces shorter RTs within spatial attention tasks (see, e.g., Henderson, 1991; Posner, Snyder, \& Davidson, 1980). Most importantly, however, discrimination performance is also improved by reduced spatial uncertainty. For example, discrimination of line length (Bonnel, Possamaï, \& Schmitt, 1987), line orientation (e.g., Cheal, Lyon, \& Hubbard, 1991), vernier stimuli (Yeshurun \& Carrasco, 1999), Landolt squares (Yeshurun \& Carrasco, 1999), and letters (e.g., Henderson, 1991) is enhanced if attention is allocated to each of these stimuli. All the studies mentioned above support the hypothesis that spatial preparation facilitates perceptual stimulus processing. Future research, however, will be necessary in order to address the question of whether the improvements in perceptual processing relating to visual spatial attention tasks, orienting of attention in time by means of a temporal cue, and temporal uncertainty are due to a common preparatory mechanism or could result from different mechanisms. It will also be important to know which specific mechanism contributes to the perceptual processing improvement caused by temporal preparation. Specifically, whereas the present results provide evidence for a signal enhancement account, it might be possible that temporal preparation also enhances signal processing by noise reduction (see Pashler, 1998).

In conclusion, the present study supports the assumption that temporal uncertainty operates at a premotoric information-processing level. Moreover, the results clearly show that reduced temporal uncertainty improves perceptual analysis, most probably by accelerating the perceptual latency for recognizing a stimulus.

\section{AUTHOR NOTE}

This study was supported by Grant RO 3034/1-1 from the Deutsche Forschungsgemeinschaft. We are grateful to Rolf Ulrich and Karin Bausenhart for their help and support. We also thank Jay Pratt, Hal Pashler, Jeff Miller, Werner Sommer, and an anonymous reviewer for helpful comments on an earlier draft of the article. Correspondence should be sent to B. Rolke, Cognitive and Biological Psychology, University of Tübingen, Friedrichstrasse 21, 72072 Tübingen, Germany (e-mail: bettina.rolke@uni-tuebingen.de). 


\section{REFERENCES}

Bachmann, T., \& Allik, J. (1976). Integration and interruption in the masking of form by form. Perception, 5, 79-97.

Bausenhart, K. M., Rolke, B., Hackley, S. A., \& Ulrich, R. (2006). The locus of temporal preparation effects: Evidence from the psychological refractory period paradigm. Psychonomic Bulletin \& Review, 13, 536-542.

Bonnel, A.-M., Possamaï, C.-A., \& Schmitt, M. (1987). Early modulation of visual input: A study of attentional strategies. Quarterly Journal of Experimental Psychology, 39A, 757-776.

Breitmeyer, B. G. (1984). Visual masking: An integrative approach. Oxford: Oxford University Press, Clarendon Press.

Brunia, C. H. M., \& van Boxtel, G. J. M. (2000). Motor preparation. In J. T. Cacioppo, L. G. Tassinary, \& G. G. Berntson (Eds.), Handbook of psychophysiology (2nd ed., pp. 507-532). Cambridge: Cambridge University Press.

Cheal, M., Lyon, D. R., \& Hubbard, D. C. (1991). Does attention have different effects on line orientation and line arrangement discrimination? Quarterly Journal of Experimental Psychology, 43A, 825-857.

Correa, A., Lupiáñez, J., \& Tudela, P. (2005). Attentional preparation based on temporal expectancy modulates processing at the perceptual level. Psychonomic Bulletin \& Review, 12, 328-334.

Coull, J. T., \& Nobre, A. C. (1998). Where and when to pay attention: The neural systems for directing attention to spatial locations and to time intervals as revealed by both PET and fMRI. Journal of Neuroscience, 18, 7426-7435.

Grice, G. R. (1968). Stimulus intensity and response evocation. Psychological Review, 75, 359-373.

HaCKley, S. A., \& Valle-InClán, F. (1998). Automatic alerting does not speed late motoric processes in a reaction-time task. Nature, $\mathbf{3 9 1}$, 786-788.

HACKLEY, S. A., \& VALLE-InCláN, F. (1999). Accessory stimulus effects on response selection: Does arousal speed decision making? Journal of Cognitive Neuroscience, 11, 321-329.

HACKLEY, S. A., \& VALLE-INCLÁN, F. (2003). Which stages of processing are speeded by a warning signal? Biological Psychology, 64, 27-45.

Hasbrouce, T., Kaneko, H., Akamatsu, M., \& Possamaï, C.-A. (1999). The time-course of preparatory spinal and cortico-spinal inhibition: An H-reflex and transcranial magnetic stimulation study in man. Experimental Brain Research, 124, 33-41.

Henderson, J. M. (1991). Stimulus discrimination following covert attentional orienting to an exogenous cue. Journal of Experimental Psychology: Human Perception \& Performance, 17, 91-106.

HoHLE, R. H. (1965). Inferred components of reaction times as functions of foreperiod duration. Journal of Experimental Psychology, 69, 382-386.

KaHNEMAN, D. (1968). Method, findings, and theory in studies of visual masking. Psychological Bulletin, 70, 404-425.

KLemmer, E. T. (1956). Time uncertainty in simple reaction time. Journal of Experimental Psychology, 51, 179-184.

LofTUs, G. R. (2002). Analysis, interpretation, and visual presentation of experimental data. In H. Pashler \& J. Wixted (Eds.), Stevens' Handbook of experimental psychology: Vol. 4. Methodology in experimental psychology (3rd ed., pp. 339-390). New York: Wiley.

LOVELESS, N. E. (1973). The contingent negative variation related to preparatory set in a reaction time situation with variable foreperiod. Electroencephalography \& Clinical Neurophysiology, 35, 369-374.

LUCE, R. D. (1986). Response times: Their role in inferring elementary mental organization. New York: Oxford University Press.

Macmillan, N. A., \& Creelman, C. D. (1991). Detection theory: A user's guide. Cambridge: Cambridge University Press.

Martens, S., \& Johnson, A. (2005). Timing attention: Cuing target onset interval attenuates the attentional blink. Memory \& Cognition, 33, 234-240.

Mattes, S., \& Ulrich, R. (1997). Response force is sensitive to the temporal uncertainty of response stimuli. Perception \& Psychophysics, 59, 1089-1097.

Miller, J., \& REYNolds, A. (2003). The locus of redundant-targets and nontargets effects: Evidence from the psychological refractory period paradigm. Journal for Experimental Psychology: Human Perception \& Performance, 29, 1126-1142.

Müller-Gethmann, H., Ulrich, R., \& Rinkenauer, G. (2003).
Locus of the effect of temporal preparation: Evidence from the lateralized readiness potential. Psychophysiology, 40, 597-611.

NiEMI, P., \& NÄÄTÄNEN, R. (1981). Foreperiod and simple reaction time. Psychological Bulletin, 89, 133-162.

Pashler, H. [E.] (1994). Dual-task interference in simple tasks: Data and theory. Psychological Bulletin, 116, 220-244.

Pashler, H. E. (1998). The psychology of attention. Cambridge, MA: MIT Press.

Pashler, H. [E.], \& Johnston, J. C. (1998). Attentional limitations in dual-task performance. In H. [E.] Pashler (Ed.), Attention (pp. 155189). Hove, U.K.: Psychology Press.

Posner, M. I., Snyder, C. R., \& Davidson, B. J. (1980). Attention and the detection of signals. Journal of Experimental Psychology: General, 109, 160-174.

Raymond, J. E., Shapiro, K. L., \& Arnell, K. M. (1992). Temporary suppression of visual processing in an RSVP task: An attentional blink? Journal of Experimental Psychology: Human Perception \& Performance, 18, 849-860.

SANDERS, A. F. (1980). Some effects of instructed muscle tension on choice reaction time and movement time. In R. S. Nickerson (Ed.), Attention and performance VIII (pp. 59-74). Hillsdale, NJ: Erlbaum.

SANDERS, A. F. (1998). Elements of human performance: Reaction processes and attention in human skill. Mahwah, NJ: Erlbaum.

Simon, J. R., \& Slaviero, D. P. (1975). Differential effects of a foreperiod countdown procedure on simple and choice reaction time. Journal of Motor Behavior, 7, 9-14.

Smith, P. L., \& WolfGang, B. J. (2004). The attentional dynamics of masked detection. Journal of Experimental Psychology: Human Perception \& Performance, 30, 119-136.

SMULDERS, F. T. Y. (1993). The selectivity of age effects on information processing: Response times and electrophysiology. Unpublished dissertation, University of Amsterdam.

Sommer, W., Leuthold, H., \& Schubert, T. (2001). Multiple bottlenecks in information processing? An electrophysiological examination. Psychonomic Bulletin \& Review, 8, 81-88.

Sperling, G. (1963). A model for visual memory tasks. Human Factors, 5, 19-31.

SPIJKERS, W. A. (1990). The relation between response-specificity, S-R compatibility, foreperiod duration and muscle-tension in a target aiming task. Acta Psychologica, 75, 261-277.

Sternberg, S. (2001). Separate modifiability, mental modules, and the use of pure and composite measures to reveal them. Acta Psychologica, 106, 147-246.

Teichner, W. H. (1954). Recent studies of simple reaction time. Psychological Bulletin, 51, 128-149.

TuRveY, M. T. (1973). On peripheral and central processes in vision: Inferences from an information-processing analysis of masking with patterned stimuli. Psychological Review, 80, 1-52.

Woodrow, H. (1914). The effect upon reaction time of variation in the preparatory interval. In J. Angell, H. Warren, J. Watson, \& S. Franz (Eds.), The psychological monographs (pp. 16-65). Princeton, NJ: Psychological Review Co.

YeshuRun, Y., \& CARRASCO, M. (1999). Spatial attention improves performance in spatial resolution tasks. Vision Research, 39, 293-306.

\section{NOTES}

1. In the context of the present article, the term premotoric refers to perceptual and central processing stages. Thus, this term includes motor preparation processes like response selection but excludes response execution.

2. In an additional ANOVA, RTs above and below two standard deviations from the mean of the entire sample were defined as outliers and were rejected $(4.7 \%)$. This analysis revealed the same pattern of results for all dependent variables.

3 . The following equation was used to calculate $d^{\prime}: d^{\prime}=z$ (hit) $z$ (false alarm) (Macmillan \& Creelman, 1991).

4. The following equation was used to calculate response bias: $c($ criterion $)=-0.5[z($ hit $)+z($ false alarm $)]$ (Macmillan \& Creelman, 1991).

(Manuscript received February 15, 2006; revision accepted for publication July 10, 2006.) 